\title{
$1 \quad$ Olfactory attraction of Drosophila suzukii by symbiotic acetic acid bacteria
}

2

3 Fabio Mazzetto ${ }^{1}$, Elena Gonella ${ }^{1}$, Elena Crotti $^{2}$, Violetta Vacchini ${ }^{2}$, Michail Syrpas ${ }^{3}$, Marianna

4 Pontini $^{1}$, Sven Mangelinckx ${ }^{3}$, Daniele Daffonchio ${ }^{4,2}$, Alberto Alma $^{1 *}$

5

$6 \quad{ }^{1}$ Dipartimento di Scienze Agrarie, Forestali e Alimentari (DISAFA), Università degli Studi di 7 Torino, Largo P. Braccini 2, 10095 Grugliasco, Italy

$8 \quad{ }^{2}$ Dipartimento di Scienze per gli Alimenti, la Nutrizione e l'Ambiente (DeFENS), Università degli

9 Studi di Milano, via Celoria 2, 20133 Milano, Italy

$10{ }^{3}$ Department of Sustainable Organic Chemistry and Technology, Ghent University, Coupure links

11653,9000 Gent, Belgium

$12{ }^{4}$ Biological and Environmental Sciences and Engineering Division (BESE), King Abdullah

13 University of Science and Technology (KAUST) Thuwal 23955-6900, Kingdom of Saudi Arabia.

14 *Corresponding Author: alberto.alma@unito.it, Phone +39 011 6708534, Fax +39 0116708535 


\section{Author contributions}

19 FM, EG, EC, SM and AA conceived of and designed the research. FM, VV, MS and MP conducted

20 the experiments. SM and DD contributed materials and tools and FM analyzed the data. FM and EG

21 wrote the manuscript. All authors read and approved the manuscript.

22

\section{Acknowledgements}

24 The authors are grateful to Enrico Busato and Marco Pansa for insect rearing and technical support. 


\section{Abstract}

Some species of acetic acid bacteria $(\mathrm{AAB})$ play relevant roles in the metabolism and physiology of Drosophila spp. and in some cases convey benefits to their hosts. The pest Drosophila suzukii harbors a set of AAB similar to those of other Drosophila species. Here, we investigate the potential to exploit the ability of $\mathrm{AAB}$ to produce volatile substances that attract female $D$. suzukii. Using a two-way olfactometer bioassay, we investigate the preference of $D$. suzukii for strains of AAB, and using gas solid phase microextraction chromatograpy-mass spectrometry we specifically characterize their volatile profiles to identify attractive and non-attractive components produced by strains from the genera Acetobacter, Gluconobacter and Komagataeibacter. Flies had a preference for one strain of Komagataeibacter and two strains of Gluconobacter. Analyses of the volatile profiles from the preferred Gluconobacter isolates found that acetic acid is distinctively emitted even after two days of bacterial growth, confirming the relevance of this volatile in the profile of this isolate for attracting flies. Analyses of the volatile profile from the preferred Komagataeibacter isolate showed that a different volatile in its profile could be responsible for attracting D. suzukii. Moreover, variation in the concentration of butyric acid derivatives found in some strains may influence the preference of D. suzukii. Our results indicate that Gluconobacter and Komagataeibacter strains isolated from $D$. suzukii have the potential to provide substances that could be exploited to develop sustainable mass-trapping-based control approaches.

\section{Keywords}

Spotted wing drosophila, Insect symbionts, Olfactometer bioassays, Volatile profile analysis, Gluconobacter, Komagataeibacter 
- Environmentally friendly strategies for the management of D. suzukii, like mass trapping, could benefit from identifying new efficient and specific lures to improve traps designed to control this pest.

- This work demonstrated that different acetic acid bacteria isolated from D. suzukii have attractive effects on female flies which may be exploited for bait development.

- Many of volatile substances produced by these strains appear to have essential roles in modulating D. suzukii preference as well. 


\section{Introduction}

Acetic acid bacteria (AAB) are Gram-negative bacteria belonging to the family Acetobacteraceae within the class Alphaproteobacteria. Their taxonomy, molecular biology and physiology have been scrutinized because of their importance in commercial food and chemical compound production (Raspor and Goranovič 2008). AAB are pervasive in the environment and easy to isolate from various plants, flowers, fruits and garden soil (Raspor and Goranovič 2008; Crotti et al. 2010).

Although some strains are spoilage agents of wine and beer and others cause plant diseases (Rohrbach and Pfeiffer 1975; van Keer et al. 1981; du Toit and Pretorius 2000; Bartowsky et al. 2003), numerous studies have also established symbiotic associations between AAB and insects that feed on sugar-based diets, specifically those belonging to the orders Diptera, Hymenoptera and Hemiptera (Crotti et al. 2010). Model species from the genus Drosophila, Drosophila melanogaster Meigen and Drosophila simulans Sturtevant, host several AAB strains, but predominantly those belonging to the genera Acetobacter and Gluconobacter (Cox and Gilmore 2007; Ren et al. 2007; Chandler et al. 2011; Wong et al. 2011; Kim et al. 2012; Staubach et al. 2013; Wong et al. 2013); strains belonging to the genera Gluconacetobacter and Commensalibacter have also been isolated from some D. melanogaster populations (Roh et al. 2008).

The insect midgut is a favorable niche for growth of AAB because of the availability of carbohydrate-rich food in an aerobic, acidic environment. Meanwhile, AAB can convey numerous advantages to their hosts, such as improving their digestive opportunities or by positively influencing larval development (Crotti et al. 2010; 2011; Chouaia et al. 2012). Some AAB are implicated in maintaining the immune homeostasis or increasing the lifespan and fitness of their hosts (Ryu et al. 2008; Shin et al. 2011), while others could be involved in defense against other harmful microorganisms or may participate in cell-to-cell communication (Crotti et al. 2010). Therefore, the relationship between $\mathrm{AAB}$ bacteria and their hosts is considered to be mutually symbiotic. 
$\mathrm{AAB}$ produce a number of volatile compounds as secondary metabolites in addition to acetic acid (Raspor and Goranovič 2008), some of which may attract host insects and facilitate the ingestion of bacteria, as reported for other symbionts (Davis et al. 2013). Pseudomonas putida has been shown to produce volatiles that attract the olive fly, Bactrocera oleae Gmelin (Liscia et al. 2013), and numerous bacteria have been shown to produce volatiles that attract the Oriental fruit fly, Bactrocera dorsalis (Hendel), and the Mexican fruit fly, Anastrepha ludens (Loew) (Jang and Nishijima 1990; Robacker et al. 1998). Similarly, a recent study on yeasts isolated from the larval frass and adult midguts of spotted-wing drosophila, Drosophila suzukii Matsumura, and their fruit food source, found a specific association between the flies and some yeasts with a preference for Hanseniaspora uvarum (Scheidler et al. 2015). The volatile compounds produced by mutualistic microorganisms living inside host insects that have a symbiotic relationship with plants might trigger their trophic interaction (Frago et al. 2012). In the case of pest insects, exploiting the relationships between bacteria, their hosts and plants may be a useful tool for developing sustainable control strategies.

Drosophila suzukii, recently introduced from Asia (Asplen et al. 2015), is currently one of the most serious threats to fruit production in Europe and North America. It was found to host several strains of AAB (Chandler et al. 2014) and their presence were also detected in a recent companion study conducted by Vacchini et al. (submitted). However, the attractiveness of the bacterial volatiles has not yet been investigated. Here, we use a two-way olfactometer to assess the preference of flies for AAB symbionts versus the control. We then characterize their volatile profiles by gas chromatography-mass spectrometry analysis. This survey could allow to evaluate differences in fly preference among strains and species of symbiotic AAB; along with identifying volatiles emitted by attractive bacteria. These compounds may be very useful for sustainable mass-trapping $D$. suzukii management programs. 


\section{Insect material and bacterial strains}

110 In the summer of 2014, we collected D. suzukii larvae on blueberries, raspberries and blackberries

111 in orchards of the Cuneo and Torino provinces of Piedmont (NW Italy). Emerged insects were

112 reared in plastic cages $(24 \times 16 \times 12 \mathrm{~cm})$ containing different types of fruit (strawberries, blueberries,

113 grapes, bananas and kiwi fruits) at the Dipartimento di Scienze Agrarie, Forestali e Alimentari 114 (DISAFA) in a growth chamber at $25 \pm 1^{\circ} \mathrm{C}, 65 \pm 5 \% \mathrm{RH}$ and a $16 \mathrm{~h}: 8 \mathrm{~h} \mathrm{~L}: \mathrm{D}$ photoperiod.

115 We selected AAB strains based on previous characterizations of the isolates by Vacchini et al. 116 (submitted), including the most commonly found genera in Italian populations of $D$. suzukii: two 117 isolates from the genus Acetobacter (A. persici DS4MR.45 and A. cibinongensis DS5FR.4), two 118 isolates from the genus Gluconobacter ( $G$. oxydans DS1FC.9A and $G$. kanchanaburiensis 119 L2.2.A.15) and two isolates from the genus Komagataeibacter (DS2MC.114 and DS1MA.65A). 120 Universal bacterial 16S rRNA gene primers 27F (5'-TCG ACA TCG TTT ACG GCG TG-3') and 121 1495R (5'-CTA CGG CTA CCT TGT TAC GA-3') were used to amplify the 16S rRNA gene from the 2 strains $K$. hansenii and $K$. saccharivorans, as previously described (Mapelli et al. 2013). Nearfull-length sequencing $16 \mathrm{~S}$ rRNA was performed and consensus sequences were compared to the

124 public databases at the National Center for Biotechnology Information using BLASTn (Altschul et 125 al. 1990); near-full-length 16S rRNA sequences were deposited in the European Nucleotide 126 Archive's database under the accession numbers LN901337 and LN901338.

\section{Two-way olfactometer bioassays}

Selected AAB strains were tested against the control (sterile growth medium) with a two-way

129 olfactometer assay to evaluate the preferences of $D$. suzukii. Isolates were cultured on liquid MA 130 medium $(10.0 \mathrm{~g} / \mathrm{l}$ glucose, $10.0 \mathrm{~g} / 1$ glycerol, $10.0 \mathrm{~g} / 1$ meat peptone, $5.0 \mathrm{~g} / 1$ yeast extract and $1 \%$ 131 ethanol) for 24 hours at $30^{\circ} \mathrm{C}$. Cells were harvested following centrifugation $(10 \mathrm{~min}, 3000 \mathrm{~g})$ and 132 adjusted to a concentration of $10^{8} \mathrm{cells} / \mathrm{ml} ; 100 \mu \mathrm{l}$ of the bacterial suspensions were then plated in 133 plastic flasks containing $20 \mathrm{ml}$ of solid MA (obtained by adding $1.5 \%$ agar) and grown at $30^{\circ} \mathrm{C}$ for 13424 or $48 \mathrm{~h}$. The comparison between two sterile MAs serving as a blank was also performed. 
Olfactometer assays were conducted following Mazzetto et al. (2015). The olfactometer consisted

136 of a plastic box $(24 \times 16 \times 12 \mathrm{~cm})$ covered with a fine mesh net on the top, and a layer of wet cotton

137 on the base to promote humidity. On the bottom of the box, there were two holes (31 mm diameter)

138 closed by silicon plugs. Two glass funnels ( $46 \mathrm{~mm}$ diameter) were fitted in these plugs and each

139 was inserted into a $250 \mathrm{ml}$ glass flask placed below the box. An air pump (Air 275R, Sera,

140 Heinsberg, Germany) was used to supply the air necessary for the trials. Pumped air was humidified

141 and split into two $5 \mathrm{~mm}$ diameter silicon tubes, each entered first into a plastic flask (125 ml)

142 containing the strain or the sterile MA. The exit air, which was enriched with the volatile

143 compounds, was provided by another silicon tube (same diameter) into the glass flask through a

144 separate hole created in the plug, close to the funnel. The glass flasks acted as traps, and the flies

145 could not escape once they had entered.

146 The experiment was conducted in a climatic chamber $\left(25 \pm 1^{\circ} \mathrm{C}, 65 \pm 5 \% \mathrm{RH}\right)$. At the beginning of the 147 experiments, illuminance (9 lux) was measured with a luxmeter (PCE-172, PCE Group, Lucca, 148 Italy) and the rate of airflow (0.25 1/min) was measured with a digital anemometer (TA-410, PCE

149 Group, Lucca, Italy) at the downwind end. For each trial, 2-10-d old D. suzukii females were 150 separated from males according to the external genitalia (Hauser 2011) and females were starved on $151 \quad 1.5 \%$ agar $(15 \mathrm{ml})$ for $24 \mathrm{~h}$ inside into a plastic tube (30 diameter, height $114 \mathrm{~mm})$. Seventy females were then introduced to the center of the olfactometer box through a small hole created in the middle of the net and closed with a plug. After $24 \mathrm{~h}$, we counted the number of flies in the box (no choice) and in each of the two flasks (one containing the volatiles of AAB strain and the other containing the volatiles of the sterile MA). Nine replicates at 24 and $48 \mathrm{~h}$ of bacterial growth were 156 carried out; nine replicates of comparisons between two MA controls were assessed too. All flasks, 157 funnels, plugs and tubes were cleaned with neutral soap and distilled water and sterilized in an 158 autoclave; the box and the net were cleaned with neutral soap, distilled water and ethanol $(70 \%$ $159 \mathrm{v} / \mathrm{v}$ ). The numbers of flies in the test trap, control trap and those remaining alive in the cage (about $16090 \%$ ) were compared by a Friedman-ANOVA followed by Wilcoxon signed-rank tests with a 
161 Bonferroni correction factor $(\mathrm{P}<0.05)$. Statistical analyses were performed through SPSS Statistics

162

163

164

165

166

167 22 (IBM Corp. Released 2013, Armonk, NY).

\section{Volatile profile analysis}

After testing the preference of flies for cultured AAB strains versus the control, volatile profiles produced by these isolates were studied. Before the analysis of volatiles, bacteria were grown at $30^{\circ} \mathrm{C}$ in liquid MA medium. The cells were adjusted to $10^{8}$ cells $/ \mathrm{ml}$ as explained above and then incubated on Petri dishes containing solid MA at $30^{\circ} \mathrm{C}$ for 24 or 48 hours.

Prior to analyses, 20-ml glass vials (Supelco Inc., Bellefonte, USA) were filled with $4 \mathrm{~g}$ of solid $\mathrm{MA}+$ bacteria and $4 \mathrm{~g}$ of $\mathrm{NaCl}$ and crushed with a spoon. The vials were closed with PTFE septa and open-top polypropylene (Supelco) caps. Sterile solid MA and $4 \mathrm{~g}$ of $\mathrm{NaCl}$, crushed in the vial was also used as control. The samples were shacked for $2 \mathrm{~min}$ at $50^{\circ} \mathrm{C}$ to accelerate equilibrium of headspace volatile compounds between the solid matrix and the headspace. Volatile compounds were extracted by solid-phase microextraction (SPME) by inserting a carboxenpolydimethylsiloxane fiber (black, 75- $\mu$ m-thick film, 23-Ga needle, Supelco, Bellefonte, PA, USA) for $30 \mathrm{~min}$ at $50^{\circ} \mathrm{C}$. After extraction, samples were desorbed into a CIS-4 programed temperature vaporization injector (Gerstel, Mülheim an der Ruhr, Germany). The volatile compounds were analyzed using an HP 6890 Series gas chromatography (GC) system equipped with a capillary column (DB-5MS, $30 \mathrm{~m} \times 0.250 \mathrm{~mm}, 0.25-\mu \mathrm{m}$-thick film). Helium gas was used as the carrier gas at a constant flow of $1.2 \mathrm{ml} / \mathrm{min}$. Oven temperature of the $\mathrm{GC}$ was programmed for a $29.33 \mathrm{~min}$ total running time. From an initial temperature of $35^{\circ} \mathrm{C}$, the temperature was increased at a constant rate of $5^{\circ} \mathrm{C} / \mathrm{min}$ up to $100^{\circ} \mathrm{C}$ and then $15^{\circ} \mathrm{C} / \mathrm{min}$ up to $300^{\circ} \mathrm{C}$ where it was held constant for $1 \mathrm{~min}$. A HP 5973 Mass Selective Detector (Hewlett-Packard, Wilmington, NC, USA) connected with the GC system was operated in electron impact mode with an electron impact energy of $70 \mathrm{eV}$. GC-MS data were processed with the MSD-Chemstation software (Agilent Technologies). Volatile compounds were initially identified by comparison of chromatographic retention times and mass spectra with 
the WILEY6N.L and NIST98.I databases and only those showing match quality higher than $75 \%$ were considered for analyses. Next the volatiles were identified by comparison with authentic standards $(1 \mu \mathrm{l} / \mathrm{ml}$ concentrated) in $10 \mathrm{ml}$ of distilled water in glass vials $(20 \mathrm{ml})$ capped with a Teflon-lined septum and analyzed with GC-MS. Alkanes $\left(\mathrm{C}_{5}\right.$ to $\left.\mathrm{C}_{18}\right)$ were also run with $4 \mathrm{~g}$ of solid $\mathrm{MA}+4 \mathrm{~g}$ of $\mathrm{NaCl}$ to calculate retention indices $(\mathrm{RI})$ for the volatiles.

Six replicates were performed for each strain and for the control (three replicates after $24 \mathrm{~h}$ growth and three replicates after $48 \mathrm{~h}$ ) and the mean percentage of each compound found according to the total peak area integrated by the analysis program in the three replicates of each strain was calculated.

\section{Chemicals}

Ethanol (Chem-Lab, $\geq 99.8 \%$ ) acetic acid (Acros Organics, 99.5\%), 2-propanol (Acros Organics, 99.5+\%), 2-propanone (Acros Organics, 99.8\%), 2-methylpropanoic acid (Acros Organics, 99+\%), 2-methylbutanoic acid (Acros Organics, 98\%), 3-methylbutanoic acid (Acros Organics, 99\%), benzaldehyde (Acros Organics, 98+\%) and acetaldehyde (Acros Organics, 99.5\%). The alkanes: pentane (Acros Organics, 99+\%), hexane (Sigma-Aldrich, $\geq 97.0 \%$ ), heptane (Sigma-Aldrich, $\geq 99 \%$ ), octane (Sigma-Aldrich, 98\%), nonane (Sigma-Aldrich, 99\%), decane (Sigma-Aldrich, $\geq 99 \%$ ), undecane (Sigma-Aldrich, $\geq 99 \%$ ), dodecane (Sigma-Aldrich, $\geq 99 \%$ ), tridecane (Acros Organics, 99+\%), tetradecane (Sigma-Aldrich, $\geq 99 \%$ ), pentadecane (Sigma-Aldrich, $\geq 99 \%$ ), hexadecane (Acros Organics, 99\%), heptadecane (Sigma-Aldrich, 99\%) and octadecane (SigmaAldrich, 99\%).

\section{Results}

\section{Identification of volatile-producing AAB strains}

To perform the two-way olfactometer bioassays experiments, we selected six AAB strains, two isolates from the genus Acetobacter (A. persici DS4MR.45 and A. cibinongensis DS5FR.4), two 
213 from the genus Gluconobacter (G. oxydans DS1FC.9A and G. kanchanaburiensis L2.2.A.15) and 214 two from the genus Komagataeibacter (DS2MC.114 and DS1MA.65A). Sequencing of near-full215 length $16 \mathrm{~S}$ rRNA gene of the two isolates from Komagataeibacter genus was performed to obtain 216 more information on their taxonomic identification. Results indicated that DS2MC.114 and 217 DS1MA.65A showed 99\% identity with Komagataeibacter hansenii and 100\% identity with 218 Komagataeibacter saccharivorans, respectively.

\section{Two-way olfactometer bioassays}

Results of the two-way olfactometer bioassays, statistical analyses with significant differences and the rate of no choice are reported in Table 1 and Figures 1-2.

First, we tested the response of $D$. suzukii to two identical stimuli (sterile MA) and found a high percentage of no choice in nine replicates and no difference between the two flasks. Thereafter, each AAB isolate was compared with the control. Flies showed a significant preference for G. oxydans, G. kanchanaburiensis and K. saccharivorans strains over the control (sterile MA) after both 24 and $48 \mathrm{~h}$ of growth (Figs. 1-2). Moreover, response to these strains had the lowest percentages of no choice after 24 and $48 \mathrm{~h}$ of bacterial growth; the strain of $K$. saccharivorans had the lowest rate of no choice (Table 1). No significant difference was found in the comparison between A. persici strain and the control in the first $24 \mathrm{~h}$ of growth, accompanied by a high percentage of no choice; however, after $48 \mathrm{~h}$ of bacterial growth, flies significantly preferred the control and the rate of no choice decreased. No preference was found for the two remaining strains after 24 or $48 \mathrm{~h}$, with a high percentage of no choice: the rate of no choice was around $50 \%$ for $K$. hansenii strain and over $23460 \%$ for A. cibinogensis strain (Figs. 1-2).

\section{Volatile profile analysis}

237 The volatile profiles of the bacterial strains and the control included alcohols, ketones, carboxylic 238 acids and aldehydes (Table 2). The analysis of compounds conducted on 24- and 48-h-old sterile 
media for the control confirmed a constant emission of ethanol (66-70\%), 2-propanol $(\sim 30 \%)$ and 240 benzaldehyde $(0.2 \%)$ (Table 2$)$.

241 Concerning $\mathrm{AAB}$, in the first $24 \mathrm{~h}$, all strains produced 2-propanone and acetic acid with the exception of $A$. persici, where acetic acid was not found in any of the three replicates. The relative amount of 2-propanone produced was similar within genera: Acetobacter strains (above 65\%), Komagataeibacter strains (approximately 50\%) and Gluconobacter strains (less than 20\%). Ethanol was still detectable in G. oxydans, G. kanchanaburiensis and K. saccharivorans strains and always below 3\%. Both Gluconobacter and A. cibinogensis were the only strains where 2-propanol was found. All butyric acid derivatives identified in this work (2-methylpropanoic acid, 2methylbutanoic acid and 3-methylbutanoic acid) were produced in the first 24 h by $A$. persici and $K$. hansenii, while $K$. saccharivorans produced only one derivative (2-methylpropanoic acid). Moreover, the cumulative relative presence of butyric acid derivatives of A. persici $(\sim 28 \%)$ was double that of $K$. hansenii and quadruple that of $K$. saccharivorans strain. Finally, the Gluconobacter strains were the only where benzaldehyde was present, although only below $2 \%$, and $K$. saccharivorans was the only strain to produce acetaldehyde, although only at about $7 \%$. After $48 \mathrm{~h}$ of bacterial growth, 2-propanone was the sole compound continuing to be released by all strains of bacteria (Table 2), and although a decrease in percentage was observed for all strains with the exception of $K$. saccharivorans (66\%), Acetobacter strains still had high relative abundance (> $50 \%$ ) of 2-propanone in the volatile profiles. Even though acetic acid was present in all strains after $24 \mathrm{~h}$ of growth, with the exception of A. persici, it was only detected in G. oxydans and G. kanchanaburiensis after $48 \mathrm{~h}$, although in increased relative abundance. In these two strains the 260 presence of 2-propanol was still recorded. After $48 \mathrm{~h}$, the cumulative production of the butyric acid 261 derivatives increased for all strains that expressed them at $24 \mathrm{~h}$ with the addition of $A$. cibinogensis strain ( 37\% relative production); neither Gluconobacter strain produced these derivatives. After $48 \mathrm{~h}$, no remnant of ethanol or acetaldehyde was present but for G. kanchanaburiensis an emission of less than $1 \%$ benzaldehyde was still detected. 


\section{Discussion}

266 The Acetobacteraceae family was confirmed to include some of the most important bacteria 267 associated with $D$. suzukii, similar to those found for other species from the Drosophilidae family 268 (Chandler et al. 2011). Olfactometer bioassays of six AAB strains among those isolated from $D$. 269 suzukii in our companion study (Vacchini et al. submitted) showed that female flies have a 270 significant attraction for half of the tested isolates with percentage of choice comparable to those 271 obtained by other authors, either on fruits (Abraham et al. 2015) and on apple cider vinegar 272 (Mazzetto et al., 2015). Flies always showed an attraction for G. oxydans, G. kanchanaburiensis and $273 K$. saccharivorans strains, no attraction for A. cibinogensis and K. hansenii and no attraction for $A$. 274 persici at 24 hours but rejection at 48 hours.

275 We performed SPME/GC-MS to characterize the attractive and non-attractive profiles of volatiles 276 of each strain. Qualitative and quantitative differences were identified in the volatile profiles of the 277 six bacterial strains, including high variability between 24 and 48 hours of bacterial growth.

278 Considerable differences were evident from the volatile profiles of the preferred strains, which 279 included both Gluconobacter isolates and K. saccharivorans. This last strain was the most highly 280 preferred for the duration of the experiment and had the lowest average rate of no choice both after 28124 and 48 hours bacterial growth (Figs. 1-2). Gluconobacter oxydans and G. kanchanaburiensis 282 produced the highest percentage of acetic acid and from both strains ethanol was emitted in the first 28324 hours. Similarly, for K. saccharivorans ethanol emission and acetic acid production was present 284 in the first 24 hours. These compounds are known to be attractive substances to Drosophila, 285 including D. suzukii (West 1961; Reed 1938; Cha et al. 2012; Landolt et al. 2012), and their 286 combined presence could be one of the keys of fly attraction. Moreover, although 2-propanone was 287 the only compound released by all bacteria throughout the experiment, its relative production was 288 the lowest in Gluconobacter strains (Table 2). Instead, the most attractive strain, K. saccharivorans, 289 produced relatively high levels of 2-propanone after 24 hours and even higher levels after 48 hours. 290 The role of 2-propanone is quite controversial: although this compound is reported to be a repellant 
291 for vinegar flies (Elamrani et al. 2001), Riveron et al. (2009) showed that 2-propanone can be repellent or attractive to D. melanogaster according to its concentration. Moreover, Newby and Etges (1998) reported that 2-propanone is a general attractant to D. mojavensis and can engender increased adult longevity. These evidences combined with our results suggest that 2-propanone could exhibit different effects according to its concentration and the fly species; its role for $D$. suzukii attraction must be further investigated.

Komagataeibacter saccharivorans continued to be the preferred strain despite the absence of acetic acid and ethanol after 48 hours. Perhaps having the highest production of butyric acid derivatives after 48 hours can explain why this strain was most preferred. Lactic acid bacteria are known to produce short-chain fatty acids like butyric acid derivatives that are precursors of many food flavor compounds (van Kranenburg et al. 2002); the production of butyric acid derivatives is also known in AAB. For example, 2-methylbutanoic acid, an aromatic compound found in fruits and used in the acid derivatives produced by AAB may be an attractive volatile for D. suzukii. However, no clear conclusion can be drawn because while $K$. saccharivorans strain produced the greatest amount of 2methylbutanoic acid, one strain that was not preferred (K. hansenii) and one strain that was not preferred and later rejected (A. persici) also produced this volatile. Thus, the volatile profiles from $K$. saccharivorans, $K$. hansenii and $A$. persici do not appear to explain the variety in response by $D$. suzukii. Potentially an interaction among volatiles could be involved in fly attraction. This might explain also why A. cibinogensis strain was not preferred by flies and fluctuated considerably for $D$. suzukii choice, even producing 3-methylbutanoic acid.

To rule out an effect from the volatiles produced by the medium, we also analyzed its profile and found that benzaldehyde, ethanol and 2-propanol were always present in the sterile medium. Previous research reported that benzaldehyde is attractive to D. melanogaster larvae (Larkin et al. 2010; Lavagnino et al. 2013) but has a repellent effect on adult flies (Rodrigues and Siddiqi 1978; Hoffmann 1983). Hoffmann (1985) found that four species of Drosophila were not attracted by 2- 
propanol; on the other hand ethanol is known to be an attractant to Drosophila flies (Devineni and

318 Hebrlein 2009). In our bioassays, a high percentage of no choice and an equal distribution between 319 the two control flasks was recorded (Figs. 1-2), indicating that this blend has little effect on 320 attraction of D. suzukii females. Moreover, some of the compounds detected in the medium could 321 be involved in bacterial metabolism, as suggested by absence of the medium-related volatiles in the 322 control in half of the strains.

323 To better explain D. suzukii preference for some isolates, further studies should investigate the fly 324 responses to the single volatile (tested at different concentrations) produced by all symbiont strains. 325 Although we could not provide an overall attraction pattern to the volatile profiles of each bacterial 326 strain, we did show that Gluconobacter and $K$. saccharivorans produced the most attractive 327 volatiles. Thus, a combination of the most effective substances could be used for the optimizing the 328 traps used in Integrated Pest Management of $D$. suzukii. Despite intensive research on specific 329 chemical substances (Landolt et al. 2012; Cha et al. 2013; 2014; 2015; Burrack et al. 2015), a clear 330 direction to resolve the current problem of $D$. suzukii as a pest has not yet been established. Traps 331 developed in the last few years have been unable to prevent crop damage while killing many non332 target insects (Iglesias et al. 2014; Asplen et al. 2015). Because the biology of AAB is already well 333 known and because they are currently used extensively in biotechnological applications (Saichana 334 et al. 2015), the exploitation of these D. suzukii symbionts has potential for the development of 335 attractive and selective traps for their management.

\section{References}

Abraham J, Zhang A, Angeli S, Abubeker S, Michel C, Feng Y, Rodriguez-Saona C (2015) Behavioral and antennal responses of Drosophila suzukii (Diptera: Drosopohilidae) to volatiles from fruit extracts. Environ Entomol 44:356-367

341 Altschul SF, Gish W, Miller W, Myers EW, Lipman (1990) Basic local alignment search tool. J 
Asplen MK, Anfora G, Biondi A, Choi D-S, Chu D, Daane KM, Gibert P, Gutierrez AP, Hoelmer KA, Hutchison WD, Isaacs R, Jiang Z-L, Kárpáti Z, Kimura MT, Pascual M, Philips CR, Plantamp C, Ponti L, Vétek G, Vogt H, Walton VM, Yu Y, Zappalà L, Desneux N (2015) Invasion biology of spotted wing Drosophila (Drosophila suzukii): a global perspective and future priorities. J Pest Sci 88:469-494

Bartowsky EJ, Xia D, Gibson RL, Fleet GH, Henschke PA (2003) Spoilage of bottled red wine by acetic acid bacteria. Lett Appl Microbiol 36:307-314

Burrack HJ, Asplen M, Bahder L, Collins J, Drummond FA, Guédot C, Isaacs R, Johnson D, Blanton A, Lee JC, Loeb G, Rodriguez-Saona C, van Timmeren S, Walsh D, McPhie DR (2015) Multistate comparison of attractants for monitoring Drosophila suzukii (Diptera: Drosophilidae) in blueberries and caneberries. Environ Entomol 44(3):704-712

Cha DH, Adams T, Rogg H, Landolt PJ (2012) Identification and field evaluation of fermentation volatiles from wine and vinegar that mediate attraction of Spotted Wing Drosophila, Drosophila suzukii. J Chem Ecol 38:1419-1431

Cha DH, Hesler SP, Cowles RS, Voght H, Loeb GM, Landolt PJ (2013) Comparison of a synthetic chemical lure and standard fermented baits for trapping Drosophila suzukii (Diptera: Drosophilidae). Environ Entomol 42:1052-1060

Cha DH, Adams T, Werle CT, Sampson BJ, Adamczyk JJ, Rogg H, Landolt PJ (2014) A fourcomponent synthetic attractant for Drosophila suzukii (Diptera: Drosophilidae) isolated from fermented bait headspace. Pest Manag Sci 70:324-331

Cha DH, Hesler SP, Park S, Adams TB, Zack RS, Rogg H, Loeb GM, Landolt PJ (2015) Simpler is better: fewer non-target insects trapped with a four-component chemical lure vs. a chemically more complex food-type bait for Drosophila suzukii. Entomol Exp Appl $154: 251-260$

Chandler JA, James PM, Jospin G, Lang JM (2014) The bacterial communities of Drosophila suzukii collected from undamaged cherries. PeerJ 2:e474. doi 10.7717/peerj.474 
Chandler JA, Lang JM, Bhatnagar S, Eisen JA, Kopp A (2011) Bacterial communities of diverse Drosophila species: ecological context of a host-microbe model system. PLOS GENET 7:e1002272. doi:10.1371/journal.pgen.1002272

Chouaia B, Rossi P, Epis S, Mosca M, Ricci I, Damiani C, Ulissi U, Crotti E, Daffonchio D, Bandi C, Favia G (2012) Delayed larval development in Anopheles mosquitos deprived of Asaia bacterial symbionts. BMC Microbiol 12:S2

Cox CR, Gilmore MS (2007) Native microbial colonization of Drosophila melanogaster and its use as a model of Enterococcus faecalis pathogenesis. Infect Immun 75:1565-1576

Crotti E, Gonella E, Ricci I, Clementi E, Mandrioli M, Sacchi L, Favia G, Alma A, Bourtzis K, Cherif A, Bandi C, Daffonchio D (2011) Secondary symbionts of insects: acetic acid bacteria. In: Manipolative tennants: bacteria associated with arthropods (E. Zcori-Fein and K. Bourtzis eds.), CRC Press Taylor \& Francis Group, Boca Raton, pp 45-72

Crotti E, Rizzi A, Chouaia B, Ricci I, Favia G, Alma A, Sacchi L, Bourtzis K, Mandrioli M, Cherif A (2010) Acetic acid bacteria, newly emerging symbionts of insects. Appl Environ Microbiol 76:6963-6970

Davis TS, Crippen TL, Hofstetter RW, Tomberlin JK (2013) Microbial volatile emissions as insect semiochemicals. J Chem Ecol 39:840-859

Devineni AV, Heberlein U (2009) Preferential ethanol consumption in Drosophila models features of addiction. Curr Biol 19:2126-2132

du Toit M, Pretorius IS (2000) Microbial spoilage and preservation of wine: using weapons from nature's own arsenal - a review. S Afr J Enol Vitic 41:48-56

Elamrani A, David JR, Idaomar M (2001) Parallel changes in enzyme activity and oviposition behavior in adults of Drosophila melanogaster submitted to alcohols, acetaldehyde or acetone. Invertebr Reprod Dev 40:17-25

Frago E, Dicke M, Godfray HCJ (2012) Insects symbionts as hidden players in insect-plant interactions. Trends Ecol Evol 27:705-711 
Hauser M (2011) A historic account of the invasion of Drosophila suzukii (Matsumura) (Diptera: Drosophilidae) in the continental United States, with remarks on their identification. Pest Manag Sci 67:1352-1357

Hoffmann AA (1983) Bidirectional selection for olfactory response to acetaldehyde and ethanol in Drosophila melanogaster. Genet Sel Evol 15:501-518

Hoffmann AA (1985) Interspecific variation in the response of Drosophila to chemicals and fruit odours in a wind tunnel. Aust J Zool 33:451-460

Iglesias LE, Nyoike TW, Liburd OE (2014) Effect of trap design, bait type, and age on captures of Drosophila suzukii (Diptera: Drosophilidae) in berry crops. J Econ Entomol 107:1508-1518

Jang EB, Nishijima KA (1990) Identification and attractancy of bacteria associated with Dacus dorsalis (Diptera: Tephritidae). Environ Entomol 19:1726-1731

Kim E-K, Kim S-H, Nam H-J, Choi MK, Lee K-A, Choi S-H, Seo YY, You H, Kim B, Lee W-J (2012) Draft genome sequence of Gluconobacter morbifer $\mathrm{G} 707^{\mathrm{T}}$, a pathogenic gut bacterium isolated from Drosophila melanogaster intestine. J Bacteriol 194:1245

Landolt PJ, Adams T, Rogg H (2012) Trapping spotted wing drosophila, Drosophila suzukii (Matsumura) (Diptera: Drosophilidae), with combinations of vinegar and wine, and acetic acid and ethanol. J Appl Entomol 136:148-154

Larkin A, Karak S, Priya S, Das A, Ayyub C, Ito K, Rodrigues V, Ramaswami M (2010) Central synaptic mechanisms underlie short-term olfactory habituation in Drosophila larvae. Learn Memory 17:645-653.

Lavagnino NJ, Arya GH, Korovaichuk A, Fanara JJ (2013) Genetic architecture of olfactory behavior in Drosophila melanogaster: differences and similarities across development. Behav Genet 43:348-359

Liscia A, Angioni P, Sacchetti P, Poddighe S, Granchietti A, Setzu MD, Belcari A (2013) Characterization of olfactory sensilla of the olive fly: behavioral and electrophysiological 
responses to volatile organic compounds from the host plant and bacterial filtrate. J Insect Physiol 59:705-716

Mapelli F, Marasco R, Rolli E, Barbato M, Cherif H, Guesmi A, Ouzari I, Daffonchio D, Borin S (2013) Potential for plant growth promotion of rhizobacteria associated with Salicornia growing in Tunisian hypersaline soils. Bio Med Res Int 2013:248078. http//dx.doi.org/10.1155/2013/248078

Mazzetto F, Pansa MG, Ingegno BL, Tavella L, Alma A (2015) Monitoring of the exotic fly Drosophila suzukii in stone, pome and soft fruit orchards in NW Italy. J Asia Pac Entomol $18: 321-329$

Newby BD, Etges WJ (1998) Host preference among populations of Drosophila mojavensis (Diptera: Drosophilidae) that use different host cacti. J Insect Behav 11:691-712

NIST (2015) http://webbook.nist.gov/chemistry/. Accessed 21 September 2015.

Raspor P, Goranovič D (2008) Biotechological applications of Acetic Acid Bacteria. Crit Rev Biotechnol 28:101-124

Reed MR (1938) The olfactory reactions of Drosophila melanogaster Meigen to the products of fermenting banana. Physiol Zool 11:317-325

Ren C, Webster P, Finkel SE, Tower J (2007) Increased internal and external bacterial load during Drosophila aging without life-span trade-off. Cell Metab 6:144-152

Riveron J, Boto T, Alcorta E (2009) The effect of environmental temperature on olfactory perception in Drosophila melanogaster. J Insect Physiol 55:943-951

Robacker DC, Martinez AJ, Garcia JA, Bartelt RJ (1998) Volatiles attractive to the Mexican Fruit Fly (Diptera: Tephritidae) from eleven bacteria taxa. Fla Entomol 81:497-508

Rodrigues V, Siddiqi O (1978) Genetic analysis of chemosensory pathway. P Indian Acad Sci B 87:147-160 
Roh SW, Nam Y-D, Chang H-W, Kim K-H, Kim M-S, Ryu J-H, Kim S-H, Lee W-J, Bae J-W (2008) Phylogenetic characterization of two novel commensal bacteria involved with innate immune homeostasis in Drosophila melanogaster. Appl Environ Microbiol 74:6171-6177

Rohrbach KG, Pfeiffer JB (1975) The interaction of four bacteria causing pink disease of pineapple with several pineapple cultivars. Phytopathol 66:396-399

Ryu J-H, Kim S-H, Lee H-Y, Bai J-Y, Nam Y-D, Bae J-W, Lee DG, Shin SC, Ha E-M, Lee W-J (2008) Innate immune homeostasis by the homeobox gene Caudal and commensal-gut mutualism in Drosophila. Science 319:777-782

Saichana N, Matsushita K, Adachi O, Frébort I, Frebortova J (2015) Acetic acid bacteria: a group of bacteria with versatile biotechnological applications. Biotechnol Adv 33(6)2:1260-1271

Scheidler NH, Liu C, Hamby KA, Zalom FG, Syed Z (2015) Volatile codes: correlation of olfactory signals and reception in Drosophila-yeast chemical communication. Sci Rep 5:14059. doi: $10.1038 /$ srep 14059

Shin SC, Kim S-H, You H, Kim B, Kim AC, Lee K-A, Yoon J-H, Ryu J-H, Lee W-J (2011) Drosophila microbiome modulates host developmental and metabolic homeostasis via insulin signaling. Science 334:670-674

Staubach F, Baines JF, Künzel F, Bik EM, Petrov DA (2013) Host species and environmental effects on bacterial communities associated with Drosophila in the laboratory and in the natural environment. PLOS ONE: e70749.doi: 10.1371/journal.pone.0070749

Vacchini V, Gonella E, Crotti E, Prosdocimi EM, Mazzetto F, Chouaia B, Callegari M, Mapelli F, Mandrioli M, Alma A, Daffonchio D Diversity and gut localization of the acetic acid bacterial microbiome in the spotted wing fly, Drosophila suzukii. Submitted to Appl Environ Microbiol

van Keer C, Vanden Abeele P, Swings J, Gossele F, De Lay J (1981) Acetic acid bacteria as causal agents of browning and rot of apples and pears. Zentralblatt für Bakteriologie: I. Abt.Originale C: Allgemeine, angewandte und ökologische Mikrobiologie 2:197-204 
van Kranenburg R, Kleerebezem M, van Hylckama Vlieg J, Ursing BM, Boekhorst J, Smit BA, Ayad EHE, Smit G, Siezen RJ (2002) Flavour formation from amino acids by lactic acid bacteria: predictions from genome sequence analysis. Int Dairy J 12:111-121

West AS (1961) Chemical attractants for adult Drosophila species. J Econ Entomol 54:677-681

Wong AC-N, Chaston JM, Douglas AE (2013) The inconstant gut microbiota of Drosophila species revealed by 16S rRNA gene analysis. ISME J 7:1922-1932

Wong AC-N, Ng P, Douglas AE (2011) Low diversity bacterial community in the gut of the fruit fly Drosophila melanogaster. Environ Microbiol 13:1889-1900 


\section{Captions of Tables and Figure}

480 Table 1 Results of the statistical analysis of the two-way olfactometer bioassays performed after 24 481 and $48 \mathrm{~h}$ of bacterial growth. $\chi^{2}$ values from the Friedman-ANOVA, performed to evaluate the 482 differences between the number of flies that chose each of the volatiles, the control, or did not 483 choose, are reported with their significance ( $\mathrm{df}=2$ in all tests). Significance of Wilcoxon signed rank 484 tests with a Bonferroni correction factor between each strain and the control are indicated, whereas 485 differences with no choice rate were not considered.

486 Table 2 Volatile compounds identified by GC-MS analysis from six strains of AAB and in the control (sterile MA medium) after 24 and $48 \mathrm{~h}$ of bacterial growth.

Fig. 1 Results of the two-way olfactometer bioassays performed after $24 \mathrm{~h}$ of bacterial growth. Responses of $D$. suzukii females to volatile compounds produced by a control (sterile medium) and several strains of AAB: Acetobacter persici DS4MR.45, Acetobacter cibinongensis DS5FR.4, Gluconobacter oxydans DS1FC.9A, Gluconobacter kanchanaburiensis L2.2.A.15, Komagataeibacter sp. DS2MC.114 and Komagataeibacter sp. DS1MA.65A. Nine replicates were performed for each strain. Mean percentages $( \pm$ SE) on the right report the flies that did not choose either the control or the volatile. Asterisks (*) indicate significant differences between the number of flies that chose the control and the volatile according to the Friedman-ANOVA and Wilcoxon signed-rank tests with a Bonferroni correction $(\mathrm{P}<0.05)$ factor.

Fig. 2 Results of two-way olfactometer bioassays performed after $48 \mathrm{~h}$ of bacterial growth. Responses of $D$. suzukii flies to volatile compounds produced by a control (sterile medium) and several strains of AAB: Acetobacter persici DS4MR.45, Acetobacter cibinongensis DS5FR.4,

\section{Gluconobacter oxydans} DS1FC.9A, Gluconobacter kanchanaburiensis L2.2.A.15,

501 Komagataeibacter sp. DS2MC.114 and Komagataeibacter sp. DS1MA.65A. Nine replicates were performed for each strain. Mean percentages $( \pm \mathrm{SE})$ on the right report flies that did not choose 
504 of flies that chose the control and the volatile according to the Friedman-ANOVA and Wilcoxon

505 signed-rank tests with a Bonferroni correction $(\mathrm{P}<0.05)$ factor. 


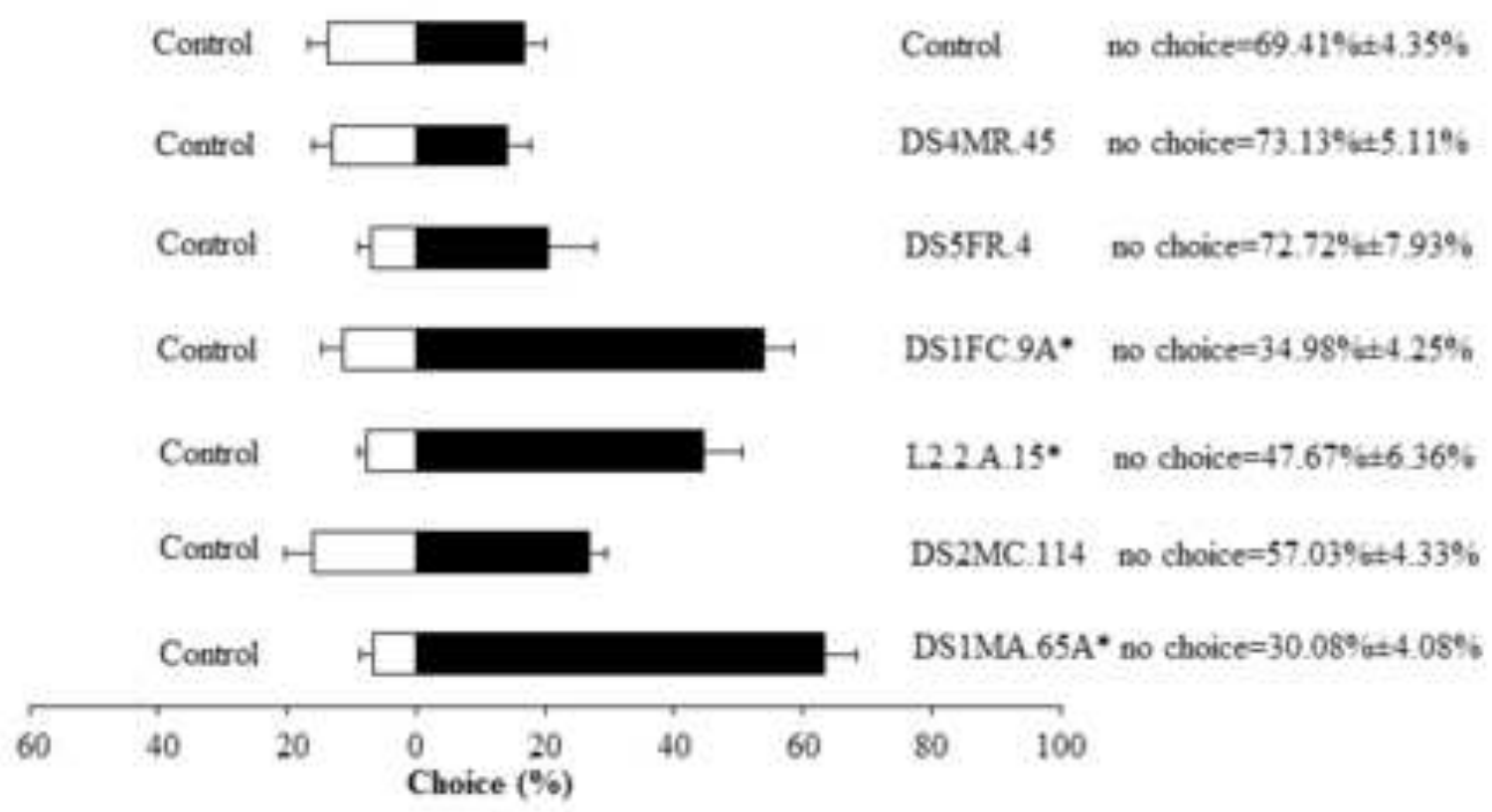




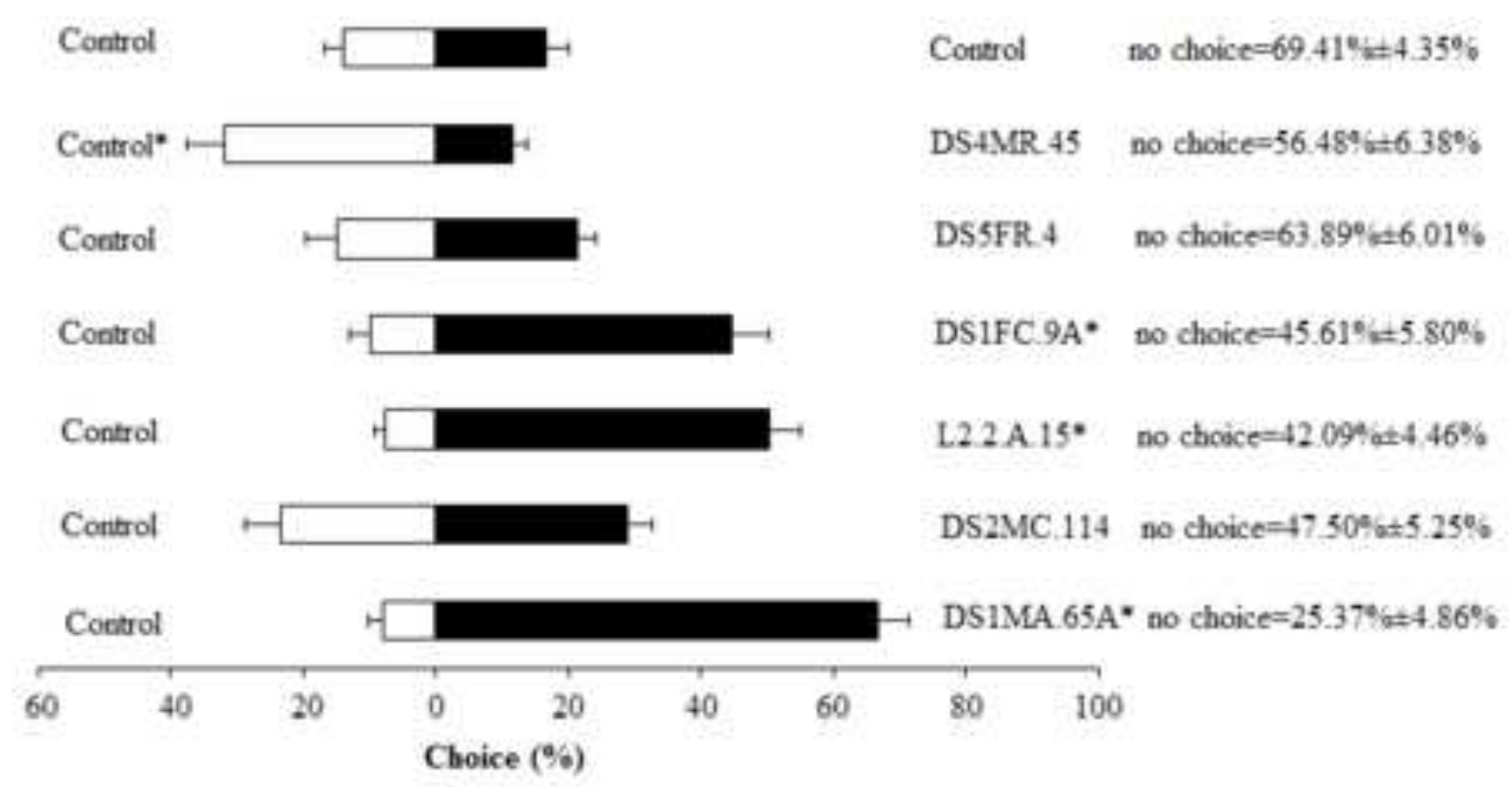


1 Table 1 Results of the statistical analysis of the two-way olfactometer bioassays performed after 24

2 and $48 \mathrm{~h}$ of bacterial growth. $\chi^{2}$ values from the Friedman-ANOVA, performed to evaluate the

3 differences between the number of flies that chose each of the volatiles, the control, or did not

4 choose, are reported with their significance ( $\mathrm{df}=2$ in all tests). Significance of Wilcoxon signed rank

5 tests with a Bonferroni correction factor between each strain and the control are indicated, whereas

6 differences with no choice rate were not considered.

7

\begin{tabular}{|c|c|c|c|c|}
\hline \multirow[t]{2}{*}{ Strain } & \multicolumn{2}{|c|}{$\begin{array}{l}\chi^{2} ; \text { significance } \\
\text { (Friedman-ANOVA) }\end{array}$} & \multicolumn{2}{|c|}{$\begin{array}{l}\text { Significance } \\
\text { (Wilcoxon signed rank test) } \\
\text { VS control }\end{array}$} \\
\hline & $24 \mathrm{~h}$ & $48 \mathrm{~h}$ & $24 \mathrm{~h}$ & $48 \mathrm{~h}$ \\
\hline Control & $14.000 ; 0.001$ & - & ns & - \\
\hline A. persici & $13.886 ; 0.001$ & $14.114 ; 0.001$ & ns & $0.012^{\mathrm{a}}$ \\
\hline A. cibinogensis & $9.556 ; 0.008$ & $11.556 ; 0.003$ & ns & ns \\
\hline G. oxydans & $12.667 ; 0.002$ & $10.889 ; 0.004$ & $0.008^{b}$ & $0.008^{b}$ \\
\hline G. kanchanaburiensis & $13.556 ; 0.001$ & $13.556 ; 0.001$ & $0.008^{b}$ & $0.008^{b}$ \\
\hline K. hansenii & $10.889 ; 0.004$ & $3.556 ; \mathrm{ns}$ & ns & ns \\
\hline K. saccharivorans & $16.222 ;<0.001$ & $13.771 ; 0.001$ & $0.008^{\mathrm{b}}$ & $0.008^{b}$ \\
\hline
\end{tabular}

8

9 ns $=$ not significant $(\mathrm{P}>0.05)$

$10{ }^{\mathrm{a}}=$ insect preference for the control versus a specific strain

$1 b^{b}=$ insect preference for a specific strain versus the control 
Table 2 Volatile compounds identified by GC-MS analysis from six strains of AAB and in the control (sterile MA medium) after 24 and $48 \mathrm{~h}$ of bacterial growth.

\begin{tabular}{|c|c|c|c|c|c|c|}
\hline \multirow[t]{2}{*}{ Strain } & \multirow[t]{2}{*}{ Compound } & \multirow[t]{2}{*}{ Identified by $^{a}$} & \multicolumn{2}{|l|}{$\mathbf{R I}^{\mathbf{b}}$} & \multicolumn{2}{|l|}{ Presence $^{c}$} \\
\hline & & & Exp. & Lit. & 24 hours & 48 hours \\
\hline \multirow{4}{*}{ A. persici } & 2-Propanone & Database; AS & ND & - & $70.6 \% \pm 1.0 \%$ & $55.0 \% \pm 5.4 \%$ \\
\hline & 2-Methylpropanoic acid & Database; AS; RI & 792 & 790 & $7.7 \% \pm 1.3 \%$ & $26.5 \% \pm 1.6 \%$ \\
\hline & 3-Methylbutanoic acid & Database; AS; RI & 878 & $876-882$ & $14.4 \% \pm 2.6 \%$ & $12.4 \% \pm 1.9 \%$ \\
\hline & 2-Methylbutanoic acid & Database; AS; RI & 875 & 876 & $7.3 \% \pm 0.1 \%$ & $6.1 \% \pm 2.6 \%$ \\
\hline \multirow{4}{*}{ A. cibinogensis } & Acetic acid & Database; AS; RI & 622 & $600-646$ & $13.0 \% \pm 3.3 \%$ & \\
\hline & 2-Propanol & Database; AS; RI & 500 & 515 & $18.4 \% \pm 1.0 \%$ & \\
\hline & 2-Propanone & Database; AS & ND & - & $68.6 \% \pm 2.5 \%$ & $63.3 \% \pm 4.9 \%$ \\
\hline & 3-Methylbutanoic acid & Database; AS; RI & 879 & $876-882$ & & $36.7 \% \pm 4.9 \%$ \\
\hline \multirow{5}{*}{ G. oxydans } & Ethanol & Database; AS & ND & - & $1.2 \% \pm 0.4 \%$ & \\
\hline & Acetic acid & Database; AS; RI & 644 & $600-646$ & $65.4 \% \pm 3.6 \%$ & $69.4 \% \pm 9.3 \%$ \\
\hline & 2-Propanol & Database; AS; RI & 501 & 515 & $17.4 \% \pm 1.2 \%$ & $17.8 \% \pm 5.1 \%$ \\
\hline & 2-Propanone & Database; AS & ND & - & $14.2 \% \pm 2.6 \%$ & $12.8 \% \pm 4.4 \%$ \\
\hline & Benzaldehyde & Database; AS; RI & 988 & 980 & $1.8 \% \pm 0.3 \%$ & \\
\hline \multirow{5}{*}{ G. kanchanaburiensis } & Ethanol & Database; AS & ND & - & $0.9 \% \pm 0.3 \%$ & \\
\hline & Acetic acid & Database; AS; RI & 644 & $600-646$ & $62.8 \% \pm 3.7 \%$ & $80.4 \% \pm 0.7 \%$ \\
\hline & 2-Propanol & Database; AS; RI & 501 & 515 & $24.5 \% \pm 2.3 \%$ & $13.9 \% \pm 0.7 \%$ \\
\hline & 2-Propanone & Database; AS & ND & - & $10.9 \% \pm 0.7 \%$ & $5.1 \% \pm 0.3 \%$ \\
\hline & Benzaldehyde & Database; AS; RI & 990 & 980 & $0.9 \% \pm 0.3 \%$ & $0.6 \% \pm 0.2 \%$ \\
\hline \multirow{5}{*}{ K. hansenii } & Acetic acid & Database; AS; RI & 629 & $600-646$ & $38.1 \% \pm 9.7 \%$ & \\
\hline & 2-Propanone & Database; AS & ND & - & $48.3 \% \pm 8.1 \%$ & $11.3 \% \pm 2.3 \%$ \\
\hline & 2-Methylpropanoic acid & Database; AS; RI & 799 & 790 & $9.8 \% \pm 1.0 \%$ & $17.2 \% \pm 1.3 \%$ \\
\hline & 3-Methylbutanoic acid & Database; AS; RI & 882 & $876-882$ & $3.5 \% \pm 0.5 \%$ & $51.3 \% \pm 0.9 \%$ \\
\hline & 2-Methylbutanoic acid & Database; AS; RI & 896 & 876 & $0.3 \% \pm 0.1 \%$ & $20.2 \% \pm 2.5 \%$ \\
\hline \multirow{7}{*}{ K. saccharivorans } & Ethanol & Database; AS & ND & - & $2.7 \% \pm 0.3 \%$ & \\
\hline & Acetic acid & Database; AS; RI & 642 & $600-646$ & $33.6 \% \pm 4.5 \%$ & \\
\hline & 2-Propanone & Database; AS & ND & - & $49.7 \% \pm 4.4 \%$ & $66.0 \% \pm 2.4 \%$ \\
\hline & 2-Methylpropanoic acid & Database; AS; RI & 790 & 790 & $6.7 \% \pm 1.6 \%$ & $2.4 \% \pm 0.5 \%$ \\
\hline & 3-Methylbutanoic acid & Database; AS; RI & 870 & $876-882$ & & $8.0 \% \pm 0.1 \%$ \\
\hline & 2-Methylbutanoic acid & Database; AS; RI & 878 & 876 & & $23.6 \% \pm 2.7 \%$ \\
\hline & Acetaldehyde & Database; AS & ND & - & $7.3 \% \pm 0.8 \%$ & \\
\hline \multirow{3}{*}{ Control (sterile MA) } & Ethanol & Database; AS & ND & - & $66.4 \% \pm 0.8 \%$ & $69.9 \% \pm 1.1 \%$ \\
\hline & 2-Propanol & Database; AS; RI & 501 & 515 & $33.4 \% \pm 0.8 \%$ & $29.9 \% \pm 1.1 \%$ \\
\hline & Benzaldehyde & Database; AS; RI & 1003 & 980 & $0.2 \% \pm 0.1 \%$ & $0.2 \% \pm 0.1 \%$ \\
\hline
\end{tabular}

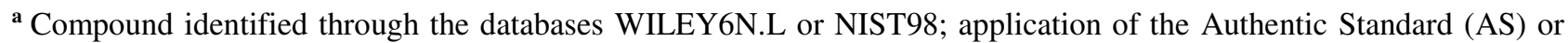
the Retention Index (RI).

b Retention index on the DB-5MS column, Exp.: RI calculated from the experiment, Lit: RI found in the literature (NIST, 2015) and ND: Not determined.

${ }^{c}$ Mean percentage \pm SE of the substance from the first, second and third replicates performed after 24 and $48 \mathrm{~h}$ of bacterial growth. 